\title{
Hubungan sikap tubuh saat bekerja dengan keluhan muskuloskeletal akibat kerja pada karyawan
}

\author{
Queena Raihan Salsabila ${ }^{1}$, Magdalena Wartono ${ }^{2}$
}

\begin{abstract}
ABSTRAK
\section{LATAR BELAKANG}

Gangguan muskuloskeletal akibat kerja adalah gangguan pada struktur muskuloskeletal pada leher, punggung, ekstremitas atas dan bawah yang disebabkan oleh mikro-trauma kumulatif akibat biomekanikal atau pajanan lain dari pekerjaan. Gangguan ini jarang mengancam jiwa, tetapi dapat meningkatkan absenteisme, menurunkan produktivitas kerja, menurunkan kualitas hidup, dan meningkatkan beban finansial. Tujuan dari penelitian ini adalah untuk mengetahui hubungan risiko sikap tubuh saat bekerja dengan timbulnya keluhan muskuloskeletal. Selain itu penelitian juga melihat faktor lain seperti masa kerja dan karakteristik jenis kelamin serta hubungannya dengan keluhan muskuloskeletal.
\end{abstract}

\section{METODE}

Penelitian menggunakan studi observasional analitik cross-sectional dengan jumlah responden 60 pekerja kantor. Risiko sikap kerja dinilai dengan menggunakan Rapid Upper Limb Assessment (RULA) dan keluhan muskuloskeletal dinilai dengan menggunakan Nordic Body Map (NBM). Selain itu juga dikumpulkan data tentang jenis kelamin dan masa kerja. Data yang dikumpulkan dianalisis dengan menggunakan uji Fisher

\section{HASIL}

Hampir sebagian besar pekerja (91.7\%) mengalami keluhan muskuloskeletal dan sebagian besar di antaranya adalah pekerja laki-laki (96.9\%). Keluhan muskuloskeletal yang tinggi didapatkan pada pekerja yang sudah bekerja lebih dari 4 tahun $(96.7 \%)$ dan juga pada pekerja dengan sikap kerja berisiko tinggi (90\%) namun berdasarkan hasil uji statistik tidak didapatkan hubungan antara jenis kelamin, masa kerja dan tingkat risiko sikap tubuh dengan keluhan muskuloskeletal ( $>00.005)$.

\section{KESIMPULAN}

Prevalensi keluhan muskuloskeletal pada pekerja kantor sangat tinggi demikian juga dengan tingkat risiko sikap tubuh saat bekerja. Pada penelitian ini tidak didapatkan hubungan antara risiko sikap tubuh, jenis kelamin dan masa kerja dengan keluhan muskuloskeletal. Dengan demikian perlu diteliti faktor-faktor lain yang mungkin menyebabkan keluhan ini. Walaupun tidak didapatkan hubungan yang bermakna, angka prevalensi yang tinggi ini perlu menjadi perhatian bagi perusahaan.

Kata kunci: masa kerja, sikap tubuh saat kerja, keluhan muskuloskeletal, pekerja kantor

\author{
${ }^{1}$ Program Studi Kedokteran, \\ Fakultas Kedokteran Universitas \\ Trisakti, Indonesia \\ 2 Departemen Anatomi, Fakultas \\ Kedokteran Universitas Trisakti, \\ Indonesia
}

\section{Korespondensi: \\ Magdalena Wartono \\ Departemen Anatomi, Fakultas \\ Kedokteran Universitas Trisakti, Indonesia \\ Jalan Kyai Tapa Kampus B, Grogol, Jakarta Barat 11440 \\ Email: magdalena_w@trisakti.ac.id}

J Biomedika Kesehat 2020;3(4):169175

DOI: 10.18051/JBiomedKes.2020. v3.169-175

pISSN: 2621-539X / eISSN: 2621-5470

Artikel akses terbuka (open access) ini didistribusikan di bawah lisensi Creative Commons Attribution 4.0 International (CC-BY 4.0) 


\section{ABSTRACT \\ Relationship between working posture and occupational muskuloskeletal complaints in office workers}

\section{BACKGROUND}

Work-related musculoskeletal disorder are disorders of the musculoskeletal structures in the neck, back, upper limbs and lower limbs caused by cumulative micro-trauma due to biomechanics or other occupational exposures. This disorder is rarely life-threatening, but can increase absenteeism, decrease work productivity and quality of life, and also increase financial burdens. The purpose of this study was to describe the risk of working posture, job-tenure and gender-differences of the employees of Bank Mandiri Tebet Supomo and its relationship with musculoskeletal complaints.

\section{METHODS}

This was a cross-sectional study with 60 employees as the respondents. The risk of working posture was assessed by Rapid Upper Limb Assessment (RULA) and musculoskeletal complaints were collected using the Nordic Body Map (NBM). Data about gender and job-tenure were also collected. The results were analyzed by Fisher's exact test.

\section{RESULTS}

Almost all of the employees had musculoskeletal complaints $(91.7 \%)$ and most of them were male $(96.9 \%)$. Musculoskeletal complaints also high in employees who had worked for more than 4 years (96.7\%) and also those within high-risk working posture $(90 \%)$. There was no relationship between gender, job-tenure and risk of working posture with musculoskeletal complaints $(\mathrm{p}>0.005)$.

\section{CONCLUSION}

The prevalence of musculoskeletal complaints among employees was very high as well as the risk of working posture. Therefore further studies were needed to determine another risk factors that caused musculoskeletal complaints. Although there was no significant relationship, this high prevalence rate needs to be a concern for companies.

Keywords: job-tenure, working posture, musculoskeletal complaints, employees

\section{PENDAHULUAN}

\section{Gangguan muskuloskeletal akibat kerja atau Work-related Musculoskeletal Disorder (WMSD) adalah gangguan pada struktur muskuloskeletal pada leher, punggung, ekstremitas atas dan bawah yang disebabkan oleh mikro-trauma kumulatif akibat biomekanikal atau pajanan lain dari pekerjaan. Gangguan ini muncul bila kapasitas adaptif dan reparasi dari struktur muskuloskeletal telah terlampaui. ${ }^{(1)}$}

Gangguan ini jarang mengancam jiwa, tetapi dapat meningkatkan absenteisme sehingga menurunkan produktivitas kerja, menurunkan kualitas hidup, meningkatkan beban finansial dan masalah kesehatan masyarakat. Di Amerika Serikat, Washington mencatat bahwa dari tahun 1999-2013, 40\% klaim kompensasi dari semua pekerja adalah berhubungan dengan WMSD, sedangkan di Inggris menurut the Labour Force Survey sekitar 6.6 juta hari kerja hilang karena WMSD, rata-rata 14 hari hilang untuk setiap kasus dan hasilnya tidak berbeda secara statistik dari tahun sebelumnya. ${ }^{(2,3)}$

Faktor-faktor yang dapat memengaruhi kejadian WMSD bisa berupa faktor individu seperti usia, jenis kelamin dan status gizi, faktor psikososial seperti stres dan juga faktor pekerjaan. Faktor pekerjaan yang telah terbukti berkaitan dengan kejadian WMSD adalah sikap atau postur tubuh yang berisiko saat bekerja, penanganan manual (manual handling) yang tidak benar, angkat berat, beban tugas yang berat, masa kerja dan gerakan repetisi. ${ }^{(4,5)}$

Zaman sekarang dengan adanya kemajuan teknologi telah membuat peralatan teknologi informasi banyak digunakan di dalam kantor, salah satunya adalah penggunaan komputer. Walaupun dapat meningkatkan efektifitas kerja, penggunaan komputer telah dikaitkan dengan peningkatan risiko gangguan muskuloskeletal. Demikian pula halnya dengan para karyawan di sektor perbankan, para karyawan ini cenderung bekerja dengan sikap tubuh/postur kerja yang tidak ergonomis, berada dalam posisi statis dalam jangka waktu yang lama, dan melakukan gerakan repetitif pada saat menggunakan komputer. Dengan demikian pekerjaan para karyawan bank membuat mereka terpapar dengan risiko terjadinya gangguan muskuloskeletal. $^{(6)}$

Prevalensi WMSD pada karyawan bank di Kuwait dilaporkan sebesar $80 \%$, sedangkan 
penelitian lainnya mendapatkan prevalensi gangguan muskuloskeletal pada 230 karyawan bank di Kumasi sebesar $83.5 \%{ }^{(6,7)}$ Bagian tubuh yang sering dikeluhkan, yaitu punggung, leher dan bahu. ${ }^{(7)}$ Demikian juga dengan penelitian sebelumnya yang membuktikan bahwa $44 \%$ dari karyawan bank mengeluh nyeri pada leher, $52 \%$ mengalami nyeri punggung bawah, dan 38\% mengalami nyeri pergelangan tangan. ${ }^{\left({ }^{(8)}\right.}$

Sikap tubuh saat bekerja merupakan salah satu faktor risiko terjadinya gangguan muskuloskeletal, hal ini dibuktikan oleh penelitian yang menunjukkan adanya korelasi kuat $(\mathrm{r}=0.9)$ antara sikap tubuh saat bekerja dengan keluhan muskuloskeletal. ${ }^{(9)}$ Akan tetapi penelitian lainnya menemukan bahwa tidak ada korelasi yang bermakna antara sikap tubuh/postur kerja dengan kejadian gangguan muskuloskeletal. ${ }^{(10)}$

Terdapat penelitian yang menemukan bahwa masa kerja (lebih dari 1 tahun) memiliki korelasi yang signifikan dengan terjadinya gangguan muskuloskeletal, tetapi tidak ada korelasi yang signifikan antara gangguan muskuloskeletal dengan jumlah jam yang dihabiskan per minggu di tempat kerja. ${ }^{(4)}$ Hal ini bertentangan dengan hasil penelitian yang menyatakan bahwa terdapat peningkatan pada gangguan muskuloskeletal dengan jumlah jam yang dihabiskan di tempat kerja. ${ }^{(1)}$ Sedangkan penelitan lainnya menyatakan bahwa pekerja yang memiliki masa kerja lebih dari 4 tahun cenderung untuk mengalami gangguan muskuloskeletal dibandingkan pekerja dengan masa kerja $<4$ tahun. ${ }^{(12)}$

Tujuan dari penelitian ini adalah untuk mengetahui risiko sikap tubuh saat bekerja, masa kerja dan karakteristik demografi (jenis kelamin) para pekerja kantor serta hubungannya dengan keluhan gangguan muskuloskeletal akibat kerja.

\section{METODE}

Jenis penelitian ini merupakan penelitian analitik observasional dengan desain crosssectional. Dalam penelitian ini, peneliti ingin mengetahui hubungan antara sikap tubuh saat bekerja dengan keluhan muskuloskeletal pada karyawan. Lokasi penelitian dilakukan di Bank Mandiri Kantor cabang Tebet Supomo, Jakarta dengan waktu penelitian pada bulan Oktober sampai dengan November 2019. Populasi pada penelitian ini adalah seluruh pekerja kantor Bank
Mandiri. Responden merupakan pekerja kantor Bank Mandiri Kantor cabang Tebet Supomo yang berusia $<60$ tahun dan bersedia mengikuti penelitian sedangkan pekerja yang dari hasil pemeriksaan fisik didapatkan Indeks Massa Tubuh (IMT) $\geq 30$, dan dari hasil wawancara memiliki riwayat kongenital berupa kelainan pada otot atau tulang, riwayat trauma otot atau tulang, serta sedang menjalani pengobatan atau konsumsi obat analgetik tidak diikutsertakan dalam penelitian ini.

Sebanyak 60 pekerja diwawancara dengan menggunakan kuesioner untuk memperoleh data jenis kelamin dan masa kerja. Untuk menilai tingkat risiko sikap tubuh kerja dilakukan pengambilan foto posisi kerja responden. Foto kemudian diukur dengan menggunakan program MB-Ruler dan dilakukan penilaian tingkat risiko sikap tubuh saat bekerja dengan menggunakan metode Rapid Upper Limb Assessment (RULA). Untuk perhitungan skor RULA, penilaian postur tubuh dibagi ke dalam 2 grup, yaitu grup A dan grup B. Postur tubuh grup A meliputi posisi lengan atas, lengan bawah, pergelangan tangan, dan putaran pergelangan tangan, sedangkan grup B meliputi leher, batang tubuh, dan kaki. Tiaptiap kategori memiliki skor penilaian postur tubuh lengkap dengan skor tambahan yang dapat digunakan sebagai bahan pertimbangan. Setelah penilaian postur tubuh, yang dilakukan selanjutnya adalah penambahan skor penggunaan otot dan penambahan faktor gaya/beban. Skor dari tiap-tiap postur tubuh dapat diperoleh dari tabel RULA. Kemudian skor total untuk grup A dan B dapat dimodifikasi tergantung jenis aktivitas otot yang terlibat dan pengerahan tenaga selama melakukan pekerjaan, sehingga akan didapatkan skor $\mathrm{C}$ dan $\mathrm{D}$ atau skor final. Bila skor final yang didapatkan adalah 1-2 menandakan sikap tubuh kerja termasuk kategori risiko rendah, sedangkan 3-4 menandakan risiko sedang, dan $\geq 5$ menandakan risiko tinggi. ${ }^{(13)}$ Data keluhan muskuloskeletal diperoleh dengan menggunakan Nordic Body Map (NBM). NBM adalah peta tubuh untuk mengetahui bagian otot yang mengalami keluhan dan tingkat keluhan yang dirasakan pekerja. NBM digunakan untuk melihat dan menganalisis letak keluhan muskuloskletal. Keluhan muskuloskeletal pada pekerja diperoleh dengan menanyakan langsung letak keluhan yang dirasakan ketika bekerja atau setelah bekerja. ${ }^{(14)}$

Analisis univariat dilakukan untuk 
menggambarkan distribusi frekuensi dari karakteristik sosiodemografi responden seperti jenis kelamin, dan juga masa kerja, risiko sikap tubuh, serta keluhan muskuloskeletal. Analisis bivariat digunakan untuk menguji hubungan antara variabel bebas dan variabel terikat dengan menggunakan uji Fisher dengan tingkat kemaknaan $<0.05$.

\section{HASIL}

Penelitian ini dilakukan pada bulan Agustus-Oktober 2019 di Bank Mandiri Kantor Cabang Tebet Supomo. Hasil penelitian menunjukkan bahwa jumlah pekerja laki-laki sedikit lebih banyak dari perempuan, yaitu sebanyak 32 orang (53.3\%). Di Tabel 1 dapat dilihat bahwa jumlah pekerja yang sudah bekerja lebih dari empat tahun setara dengan jumlah pekerja yang masa kerjanya kurang dari atau sama dengan empat tahun. Para pekerja yang bekerja dengan sikap tubuh berisiko tinggi adalah sebanyak 50 orang $(83.3 \%)$ dan yang memiliki keluhan muskuloskeletal adalah sebanyak 55 orang (91.7\%).

Tabel 1. Distribusi karakteristik subjek $(\mathrm{n}=60)$

\begin{tabular}{lc}
\hline Karakteristik & $\mathbf{n}(\mathbf{\%})$ \\
\hline Jenis kelamin & \\
Laki-Laki & $32(53.3)$ \\
Perempuan & $28(46.7)$ \\
Masa kerja & \\
$>4$ tahun & $30(50.0)$ \\
$\leq 4$ tahun & $30(50.0)$ \\
Risiko sikap tubuh saat \\
bekerja \\
$\quad$ Rendah \\
$\quad$ Sedang \\
$\quad$ Tinggi \\
Keluhan muskuloskeletal \\
$\quad$ Ya \\
Tidak & $10(16.7)$ \\
\hline Ket: & $50(83.3)$ \\
& $55(91.7)$ \\
\end{tabular}

Ket: $n=$ jumlah; $\%=$ persentasse

Hasil wawancara dengan menggunakan Nordic Body Map (Tabel 2) menunjukkan bahwa bagian tubuh yang paling sering mengalami keluhan pada pekerja kantor ini adalah bagian pinggang sebanyak 32 orang (53.3\%), kemudian bagian leher atas dan punggung yaitu sebanyak 30 orang $(50 \%)$, dan leher bawah sebanyak 28 orang
(46.6\%). Area yang paling sedikit dikeluhkan adalah bagian siku baik kiri maupun kanan.

Tabel 2. Gambaran keluhan muskuloskeletal berdasarkan bagian tubuh karyawan

\begin{tabular}{|c|c|c|c|c|}
\hline \multirow{3}{*}{ Bagian tubuh } & \multicolumn{4}{|c|}{ Keluhan Muskuloskeletal } \\
\hline & \multicolumn{2}{|c|}{ Ya } & \multicolumn{2}{|c|}{ Tidak } \\
\hline & $\mathbf{n}$ & $\%$ & $\mathbf{n}$ & $\%$ \\
\hline Leher atas & 30 & 50 & 30 & 50 \\
\hline Leher bawah & 28 & 46.6 & 32 & 53.4 \\
\hline Bahu kiri & 20 & 33.3 & 40 & 66.7 \\
\hline Bahu kanan & 21 & 35 & 39 & 65 \\
\hline Lengan atas kiri & 7 & 11.6 & 53 & 88.4 \\
\hline Punggung & 30 & 50 & 30 & 50 \\
\hline Lengan atas kanan & 10 & 16.6 & 50 & 83.4 \\
\hline Pinggang & 32 & 53.33 & 28 & 46.7 \\
\hline Buttock & 8 & 13.3 & 52 & 86.7 \\
\hline Bottom & 5 & 8.3 & 55 & 91.7 \\
\hline Siku kiri & 2 & 3.3 & 58 & 96.7 \\
\hline Siku kanan & 2 & 3.3 & 58 & 96.7 \\
\hline Lengan bawah kiri & 3 & 5 & 57 & 95 \\
\hline $\begin{array}{l}\text { Lengan bawah } \\
\text { kanan }\end{array}$ & 4 & 6.6 & 56 & 93.4 \\
\hline $\begin{array}{l}\text { Pergelangan } \\
\text { tangan kiri }\end{array}$ & 6 & 10 & 54 & 90 \\
\hline $\begin{array}{l}\text { Pergelangan } \\
\text { tangan kanan }\end{array}$ & 9 & 15 & 51 & 85 \\
\hline Tangan kiri & 9 & 15 & 51 & 85 \\
\hline Tangan kanan & 12 & 20 & 48 & 80 \\
\hline Paha kiri & 4 & 6.6 & 56 & 93.4 \\
\hline Paha kanan & 6 & 10 & 54 & 90 \\
\hline Lutut kiri & 12 & 20 & 48 & 80 \\
\hline Lutut kanan & 14 & 23.3 & 46 & 76.7 \\
\hline Betis kiri & 12 & 20 & 48 & 80 \\
\hline Betis kanan & 14 & 23.3 & 46 & 76.6 \\
\hline $\begin{array}{l}\text { Pergelangan kaki } \\
\text { kiri }\end{array}$ & 11 & 18.3 & 49 & 81.7 \\
\hline $\begin{array}{l}\text { Pergelangan kaki } \\
\text { kanan }\end{array}$ & 9 & 15 & 51 & 85 \\
\hline Kaki kiri & 9 & 15 & 51 & 85 \\
\hline Kaki kanan & 10 & 16.6 & 50 & 83.4 \\
\hline
\end{tabular}

Hasil analisis bivariat (Tabel 3) menunjukkan bahwa pekerja laki-laki memiliki keluhan muskuloskeletal lebih banyak daripada perempuan yaitu sebesar 96.9\%. Hasil uji Fisher menunjukkan bahwa tidak terdapat hubungan antara jenis kelamin dengan keluhan muskuloskeletal $(\mathrm{p}=0.138)$.

Karyawan yang bekerja $>4$ tahun lebih banyak yang mengalami keluhan muskuloskeletal yaitu sebanyak 29 orang (96.7\%). Hasil uji Fisher menunjukkan tidak ada hubungan antara masa kerja dengan keluhan muskuloskeletal dengan 
Tabel 3. Hubungan antara jenis kelamin, masa kerja, dan risiko sikap tubuh dengan keluhan muskuloskeletal

\begin{tabular}{|c|c|c|c|c|c|}
\hline \multirow{3}{*}{ Karakteristik } & \multicolumn{4}{|c|}{ Keluhan Muskuloskeletal } & \multirow{3}{*}{ nilai $\mathbf{p}^{*}$} \\
\hline & \multicolumn{2}{|c|}{ Ya } & \multicolumn{2}{|c|}{ Tidak } & \\
\hline & $\mathbf{n}$ & $\%$ & $n$ & $\%$ & \\
\hline \multicolumn{6}{|l|}{ Jenis kelamin } \\
\hline Laki-laki & 31 & 96.9 & 1 & 3.1 & 0.138 \\
\hline Perempuan & 24 & 85.7 & 4 & 14.3 & \\
\hline \multicolumn{6}{|l|}{ Masa kerja } \\
\hline$>4$ tahun & 29 & 96.7 & 1 & 3.3 & 0.177 \\
\hline$\leq 4$ tahun & 26 & 86.7 & 4 & 13.3 & \\
\hline \multicolumn{6}{|c|}{ Risiko sikap tubuh saat bekerja } \\
\hline Tinggi & 45 & 90 & 5 & 10 & 0.388 \\
\hline Sedang & 10 & 100 & 0 & 0 & \\
\hline Rendah & 0 & 0 & 0 & 0 & \\
\hline
\end{tabular}

nilai $\mathrm{p}=0.177(\mathrm{p}>0.05)$.

Hasil analisis bivariat antara variabel risiko sikap tubuh dengan keluhan muskuloskeletal menunjukkan bahwa hampir semua pekerja dengan risiko sikap tubuh tinggi memiliki keluhan muskuloskeletal (90\%) dan pada pekerja dengan risiko sikap tubuh sedang seluruhnya mengalami keluhan muskuloskeletal (100\%). Pada penelitian ini tidak didapatkan pekerja dengan risiko sikap tubuh rendah. Hasil uji bivariat menggunakan uji Fisher didapatkan nilai $\mathrm{p}=0.388 \quad(\mathrm{p}>0.05)$, sehingga dapat disimpulkan tidak terdapat hubungan antara risiko sikap tubuh dengan keluhan muskuloskeletal.

\section{PEMBAHASAN}

Hasil penelitian menunjukkan bahwa pekerja yang mengalami keluhan muskuloskeletal adalah sangat tinggi yaitu $91.7 \%$, hasil ini tidak jauh berbeda dengan penelitian sebelumnya yang mendapatkan prevalensi keluhan muskuloskeletal di kalangan pekerja bank di Kuwait sebesar $80 \%$.

(7) Hal ini menguatkan pendapat bahwa gangguan muskuloskeletal akibat kerja merupakan masalah utama dalam kesehatan kerja dan memerlukan perhatian serta tindakan preventif agar tidak berdampak terhadap produktivitas kerja. ${ }^{(15)}$

Bagian tubuh yang paling sering dikeluhkan berdasarkan hasil dari Nordic Body Map adalah pinggang (53.3\%), kemudian punggung $(50 \%)$, leher atas $(50 \%)$, dan leher bawah (46.6\%). Penelitian pada karyawan bank di Ghana juga menunjukkan hasil yang mirip yaitu pinggang (64.8\%), punggung $(61,7 \%)$, dan leher (47.4\%). ${ }^{(6)}$ Pekerja kantor biasanya termasuk golongan pekerja yang cenderung duduk lama dan sedentair, hal ini dapat menjadi pemicu meningkatnya kejadian nyeri leher dan nyeri punggung bawah. ${ }^{(16)}$

Sesuai dengan data dari Badan Pusat Statistik persentase tenaga kerja formal tahun 2018 yang berjenis kelamin laki-laki (46.10\%) lebih banyak dibandingkan perempuan (38.10\%). (17) Demikian juga dengan hasil penelitian ini di mana dari 60 pekerja kantor Bank Mandiri Cabang Tebet Supomo 53.3\% adalah laki-laki. Di antara pekerja tersebut, keluhan muskuloskeletal lebih banyak dikeluhkan oleh pekerja lakilaki $(96.9 \%)$ dibandingkan dengan perempuan (85.7\%). Hasil uji statistik menunjukkan tidak ada hubungan antara jenis kelamin dengan keluhan muskuloskeletal $(\mathrm{p}=0.138)$. Penelitian lainnya juga mendapatkan hasil demikian di mana tidak ada perbedaan yang bermakna antara jenis kelamin dengan keluhan muskuloskeletal $(\mathrm{p}=0.254)$. Pada penelitian tersebut, hasil analisis regresi didapatkan laki-laki memiliki risiko sebesar 4.1 kali untuk terjadinya keluhan muskuloskeletal. (18) Beberapa penelitian menunjukkan bahwa keluhan muskuloskeletal lebih sering terjadi pada perempuan dibandingkan pada laki-laki. ${ }^{(19,20)} \mathrm{Hal}$ ini disebabkan oleh beberapa hal seperti bentuk tubuh perempuan umumnya lebih kecil, tonus otot yang lebih rendah dan tingkat stres yang lebih tinggi. ${ }^{(19)}$ Terdapat penelian yang menunjukkan adanya hubungan antara jenis kelamin dengan keluhan muskuloskeletal di mana risiko pada perempuan adalah sebesar 3.74 kali. ${ }^{(6)}$ Perbedaan hasil penelitian ini bisa saja disebabkan oleh jumlah pekerja laki-laki yang lebih banyak dan 
faktor-faktor risiko lain yang tidak diteliti, seperti faktor psikososial berupa stres. ${ }^{(4,5)}$

Berdasarkan penelitian di lapangan, jumlah pekerja yang bekerja $>4$ tahun lebih banyak yang mengalami keluhan muskuloskeletal (96.7\%), walaupun hasil uji statistik tidak menunjukkan adanya perbedaan yang bermakna $(p=0.177)$. Penelitian sebelumnya juga menunjukkan hasil yang sama di mana jumlah karyawan bank yang telah bekerja lebih dari 5 tahun lebih banyak yang mengalami keluhan muskuloskeletal, namun tidak didapatkan hubungan yang bermakna $(\mathrm{p}=1.000) .{ }^{(21)}$ Hasil ini berbeda dengan penelitian yang dilakukan oleh Abledu et al di mana hasil penelitiannya menunjukkan masa kerja yang lama meningkatkan risiko keluhan muskuloskeletal sebesar 2.18 kali. $^{(6)}$ Perbedaan hasil penelitian ini dimungkinkan karena beban kerja di antara para karyawan, baik yang sudah bekerja lebih dari 4 tahun maupun yang kurang cenderung sama. Beban kerja mental sendiri merupakan hazard psikososial yang dapat meningkatkan risiko munculnya stres kerja. Pada individu yang mengalami stres, sensasi nyerinya akan menguat sehingga prevalensi keluhan muskuloskeletal menjadi meningkat. ${ }^{(22)}$

Pekerja dengan tingkat risiko ergonomi (sikap tubuh saat bekerja) tinggi lebih banyak dibandingkan dengan yang sedang. Terdapat penelitan yang menunjukkan bahwa kebanyakan sikap kerja adalah berisiko tinggi dan perlu segera diperbaiki. ${ }^{(9)}$ Pekerja kantor dengan risiko sikap tubuh tinggi yang memiliki keluhan muskuloskeletal sebanyak 90\% dan karyawan dengan risiko sikap tubuh sedang sebanyak $100 \%$. Hasil uji statisktik didapatkan nilai $\mathrm{p}=0.388$ sehingga dapat disimpulkan tidak terdapat hubungan yang bermakna antara risiko sikap tubuh dengan keluhan muskuloskeletal. Berbeda dengan penelitian sebelumnya yang menunjukkan adanya hubungan antara sikap tubuh yang berisiko tinggi dengan keluhan muskuloskeletal di bagian bahu, leher dan pinggang (Adjusted OR: 3.38; 5.51 dan 2.25) terutama pada pekerja perempuan. ${ }^{(23)}$ Bekerja dengan sikap tubuh yang canggung dalam durasi waktu yang lama dapat menyebabkan nyeri segmental. Sikap tubuh saat bekerja berupa posisi duduk yang lama mempunyai efek negatif terhadap diskus intervertebralis terutama berkaitan dengan nutrisi ke struktur tersebut. Hal ini berkaitan dengan mekanisme berputarnya panggul pada saat duduk sehingga menyebabkan terjadinya kiposis pada regio lumbar dari tulang belakang. Kiposis ini akan meningkatkan tekanan pada diskus dan juga otot-otot punggung sehingga lama kelamaan dapat menyebabkan nyeri di daerah tersebut. ${ }^{(24)}$ Perbedaan hasil penelitian ini mungkin disebabkan tidak adanya penilaian terhadap durasi kerja yang juga merupakan salah satu faktor risiko terjadinya keluhan muskuloskeletal, Lee JG et al, membuktikan bahwa pekerja yang bekerja lebih dari 40 jam per minggu memiliki risiko sebesar 1.5 kali mengalami gangguan muskuloskeketal. (25) Hasil penelitian ini tidak mendapatkan pekerja yang memiliki risiko sikap tubuh yang rendah, sehingga tidak dapat membandingkan antara pekerja risiko sikap tubuh rendah dengan yang tinggi. Hal ini tentu memengaruhi analisis dari hubungan kedua variabel tersebut.

Persentase keluhan muskuloskeletal dan jumlah pekerja dengan tingkat risiko sikap tubuh tinggi yang besar ini menunjukkan bahwa sikap tubuh tetap harus diperhitungkan dalam melakukan penanganan atau merancang pengendalian terhadap gangguan muskuloskeletal pada pekerja di kantor ini.

Pada penelitian ini kami memiliki keterbatasan berupa penilaian keluhan muskuloskeletal yang masih bersifat subjektif tanpa melakukan pemeriksaan fisik dan penunjang. Gangguan muskuloskeletal akibat kerja merupakan penyakit dengan penyebab multifactorial, faktor-faktor lain yang dapat memengaruhi keluhan muskuloskeletal yang lain seperti faktor lingkungan, psikososial, dan lama durasi kerja pada karyawan juga tidak diteliti.

\section{KESIMPULAN}

Hasil penelitian menunjukkan bahwa prevalensi keluhan muskuloskeletal pada karyawan bank sangat tinggi demikian juga dengan tingkat risiko sikap tubuh saat bekerja. Keluhan muskuloskeletal lebih banyak didapatkan pada laki-laki daripada perempuan dan juga pada mereka yang sudah bekerja lebih dari empat tahun. Walaupun tidak didapatkan hubungan antara jenis kelamin, masa kerja dan risiko sikap tubuh saat bekerja dengan keluhan muskuloskeletal, angka prevalensi yang tinggi ini perlu digunakan sebagai acuan untuk segera dilakukan upaya pengendalian 
bahaya potensial ergonomi terhadap para pekerja kantor bank tersebut.

\section{UCAPAN TERIMA KASIH}

Pihak Bank Mandiri kantor cabang Tebet Supomo

\section{REFERENSI}

1. Stock SR, Nicolakakis N, Vézina N, et.al. Are work organization interventions effective in preventing or reducing work-related muskuloskeletal disorders? A systematic review of the literature. Scand J Work Environ Health 2018;44(2):113133. doi:10.5271/sjweh.3696

2. Health and Safety Executive. Work related musculoskeletal disorder in Britain [Internet]. Health and Safety Executive ; 2018. Available from: www.hse.gov.uk/statistics/

3. Yang S, Lu J, Zeng J, et al. Prevalence and Risk Factors of Work-Related Musculoskeletal Disorders Among Intensive Care Unit Nurses in China. Workplace Health Saf. 2019;67(6):275287. doi: $10.1177 / 2165079918809107$

4. Sulaiman SK, Kamalanathan P, Ibrahim AA, et al. Muskuloskeletal disorders and associated disabilities among bank workers. Int J Res Med Sci. 2015;3:1153-8

5. Algarni FS, Gross DP, Senthilselvan A, et al. Ageing workers with work-related musculoskeletal injuries. Occup Med (Lond). 2015;65(3):229-37. doi: $10.1093 / \mathrm{occmed} / \mathrm{kqu} 213$

6. Abledu JK, Abledu GK. Multiple Logistic Regression Analysis of Predictors of Musculoskeletal Disorders and Disability among Bank Workers in Kumasi, Ghana. J Ergonomics. 2012;2(4):1-5. doi: 10.4172/2165-7556.1000111

7. Akrouf QA, Crawford JO, Al-Shatti AS, et al. Musculoskeletal disorders among bank office workers in Kuwait. East Mediterr Health J. 2010;16(1):94-100. PMID: 20214165.

8. Tarakci D, Tarakci E, Baydogan SN, et.al. Evaluation of Work-Related Musculoskeletal Disorders in Office Workers. Annals of the Rheumatic Diseases, suppl. 2; London. 2014;73:1223. doi:10.1136/annrheumdis-2014eular.6061

9. Gangopadhyay S, Ghosh T, Das T, et.al. Effect of working posture on occurance of musculoskeletal disorders among the sand core making workers of West Bengal. Cent Eur J Public Health. 2010;18(1): $38-42$

10. Atmojo TB, Rinawati S. Hubungan postur kerja dengan gangguan muskuloskeletal pada operator dump truck di PT. Harmoni Panca Utama. Journal of Industrial Hygiene and Occupational Health 2017;2(1):2541-57. doi:10.21111/jihoh.v2i1.946

11. Talwar R, Kapoor R, Puri K, et al. A Study of Visual and Musculoskeletal Health Disorders among Computer Professionals in NCR Delhi. Indian J Community Med. 2009;34(4):326-8. doi:10.4103/0970-0218.58392

12. Hendra, Rahardjo S. Risiko ergonomi dan keluhan muskuloskeletal disorder pada pekerja panen kelapa sawit. In: Prastawa H, Adi P, Susanto N, et al, editors. Prosiding Seminar Nasional Ergonomi IX: Ergonomics for Enhanced Quality of Work Life; 2009; Semarang. Semarang: Jurusan Teknik Industri, Fakultas Teknik Universitas Diponegoro; 2009. D11. Bagian D (Biomekanika dan Fisiologi); p. $1-8$.

13. Golchha V, Sharma $P$, Wadhwa J, et al. Ergonomic risk factors and their association with musculoskeletal disorders among Indian dentist: a preliminary study using Rapid Upper Limb Assessment. Indian J Dent Res. 2014;25(6):76771. doi: 10.4103/0970-9290.152202

14. Dewi NF. Identifikasi risiko ergonomi dengan metode Nordic Body Map terhadap perawat Poli RS X. Jurnal Spsial Humaniora Terapan. 2020;2(2):125-134. doi: 10.7454/jsht.v2i2.90

15. Soares CO, Pereira BF, Pereira Gomes MV, et al. Preventive factors against work-related musculoskeletal disorders: narrative review. Rev Bras Med Trab. 2020;17(3):415-430. doi: 10.5327/ Z1679443520190360

16. Ye S, Jing Q, Wei C, et al. Risk factors of nonspecific neck pain and low back pain in computerusing office workers in China: a cross-sectional study. BMJ Open. 2017;7(4):e014914. doi: 10.1136/bmjopen-2016-014914.

17. Badan Pusat Statistik. Persentase Tenaga Kerja Formal Menurut Jenis Kelamin 2018 [Internet]. Jakarta: Badan Pusat Statistik; 2018. Available from: https://www.bps.go.id/indicator/6/1170/1/ persentase-tenaga-kerja-formal-menurut-jeniskelamin.html

18. Batham C, Yasobant S. A risk assessment study on work-related musculoskeletal disorders among dentists in Bhopal, India. Indian J Dent Res. 2016;27:236-41. doi: 10.4103/0970-9290.186243

19. Khan SA, Chew KY. Effect of working characteristics and taught ergonomics on the prevalence of musculoskeletal disorders amongst dental students. BMC Musculoskelet Disord. 2013;14:118. doi: 10.1186/1471-2474-14-118

20. Das B. Gender differences in prevalence of musculoskeletal disorders among the rice farmers of West Bengal, India. Work. 2015;50(2):22940. doi: $10.3233 /$ WOR-131694

21. Mekonnen TH, Abere G, Olkeba SW. Risk Factors Associated with Upper Extremity Musculoskeletal Disorders among Barbers in Gondar Town, Northwest Ethiopia, 2018: A Cross-Sectional Study. Pain Res Manag. 2019;2019:6984719. doi: $10.1155 / 2019 / 6984719$

22. Hardianto, Trisnawati E, Rossa I. Faktorfaktor yang berhubungan dengan keluhan muskuloskeletal disorder pada karyawan Bank X [Internet]. JUMANTIK: Jurnal Mahasiswa dan Peneliti Kesehatan. 2015;2 (2). Available from: http://openjurnal.unmuhpnk.ac.id/index.php/ JJUM/article/view/328

23. Magnavita N, Elovainio M, De Nardis I, et al. Environmental discomfort and musculoskeletal disorders. Occup Med (Lond). 2011;61(3):196201. doi: $10.1093 /$ occmed/kqr024

24. Lapointe J, Dionne CE, Brisson C, et al. Interaction between postural risk factors and job strain on self-reported musculoskeletal symptoms among users of video display units: a three-year prospective study. Scand J Work Environ Health. 2009;35(2):134-44. doi: 10.5271/sjweh.1312

25. Pal A, Dhara PC. Evaluation of Work-Related Musculoskeletal Disorders and Postural Stress of Female "Jari" Workers. Indian J Occup Environ Med. 2017;21(3):132-137. doi: 10.4103/ijoem. IJOEM 5517

26. Lee $\mathrm{JG}^{-} \mathrm{Kim} \mathrm{GH}$, Jung $\mathrm{SW}$, et al. The association between long working hours and work-related musculoskeletal symptoms of Korean wage workers: data from the fourth Korean working conditions survey (a cross-sectional study). Ann Occup Environ Med. 2018;30:67. doi: 10.1186/ s40557-018-0278-0 